\title{
In-Vehicle Vibration Study of Child Safety Seats
}

J. Giacomin and S. Gallo

\author{
Department of Mechanical Engineering \\ The University of Sheffield \\ Mappin Street, Sheffield S1 3JD
}

\section{Tel: 0114-222-7781 Fax: 0114-222-7890 e-mail: j.a.Giacomin@sheffield.ac.uk}

\section{Summary}

This paper reports experimental measurements of the in-vehicle vibrational behaviour of stage $0 \& 1$ child safety seats. Road tests were performed for eight combinations of child, child seat and automobile. Four accelerometers were installed in the vehicles and orientated to measure as closely as possible in the vertical direction; two were attached to the floor and two located at the human interfaces. An SAE pad was placed under the ischial tuberosities of the driver at the seat cushion and a child pad, designed for the purpose of this study, was placed under the child. 4 test runs were made over a pave' (cobblestone) surface for the driver's seat and 4 for the child seat at both 20 $\mathrm{km} / \mathrm{h}$ and $40 \mathrm{~km} / \mathrm{h}$. Power spectral densities were determined for all measurement points and acceleration transmissibility functions (ATFs) were estimated from the floor of the vehicle to the human interfaces. The system composed of automobile seat, child seat and child was found to transmit greater vibration than the system composed of automobile seat and driver. The ensemble mean transmissibility in the frequency range from 1 to $60 \mathrm{~Hz}$ was found to be $77 \%$ for the child seat systems as opposed to $61 \%$ for the driver's seats. The acceleration transmissibility for the child seat system was found to be higher than that of the driver's seat at most frequencies above $10 \mathrm{~Hz}$ for all eight systems tested. The measured ATFs suggest that the principal whole-body vibration resonance of the children occurred at a mean frequency of 8.5 , rather than the 3.5 to $5.0 \mathrm{~Hz}$ typically found in 
the case of seated adults. It can be concluded that current belt-fastened child seats are less effective than the vehicle primary seating systems in attenuating vibrational disturbances. The results also suggest the potential inability of evaluating child comfort by means of existing whole-body vibration standards.

Keywords : children, child seat, vibration, vehicle, comfort

\subsection{Introduction}

Automotive seating systems have been the object of numerous studies and a large body of knowledge exists regarding the vibrational behaviour of vehicle seats with adult human occupants. Experimental procedures are used in industry (Giacomin 1995; Blaise 2001) to test the vibrational properties of the vehicle primary seating system. Little research has been performed, however, regarding the vibrational behaviour of child safety seats. These systems have been the object of numerous investigations regarding the protection they offer in case of a crash (Kuhane 1986; Bruncassan 1992) but few studies have been performed regarding the vibrational stimuli reaching the child occupant.

The title "child safety seat" describes any product which provides a safe environment for children during a crash. Anthropometric changes during childhood require that a range of products be offered to cover the various sizes of children. Rating systems are used to define the age and weight ranges that have been tested safe for each seat. The system in general use in the United Kingdom is presented in Table 1.

[insert table 1 here] 
In the international literature the only examples of investigations regarding the vibrational behaviour of child safety seats are those previously performed by one of the authors. A study by Giacomin (2000) describes measurements performed for two stage $0 \& 1$ child safety seats within the operational environment of one test vehicle when driving over two road surfaces. The study compared the vibrations measured at the interface between the driver and the driver's seat to those measured in the child seat at the interface with the child. The differences in r.m.s. and peak acceleration level were significant, with the child seat producing higher levels on both road surfaces. Another study by Giacomin (1997a) describes an investigation of the modal properties (Ewins 2000) of two stage 0\&1 child seats. The analysis found that the first resonance frequency of the child seat frame could be as low as 15 to $17 \mathrm{~Hz}$, and that three or more modes of vibration of the frame were typically present in the frequency range up to $40 \mathrm{~Hz}$. Damping was found to be from $1 \%$ to $7 \%$ critical for the vibrational modes identified. Natural frequencies, mode shapes and modal damping were found to be highly dependent on the position (up or down) of the child seat handle. A further study (Giacomin 1997b) described a device developed for the purpose of measuring, during normal driving, the vertical apparent mass of a small child. Preliminary measurements performed using the device suggested that the first whole-body resonance frequency of the seated child was different from that normally measured for adults.

The studies performed to date have measured the vibration characteristics of only a limited number of seats. The objective of the study described in this paper was to measure, for several combinations of automobile, child seat and child, the vibrations arriving at the child and to compare these to the vibrations at the interface between the driver and the automobile primary seating system. Safety and realism considerations suggested that road testing, as opposed to laboratory testing, would be the best approach for the study. Stage $0 \& 1$ products were investigated.

\subsection{Experiment}


Data acquisition and analysis was performed by means of a Larson Davis Model 2900B portable spectrum analyzer (Larson Davis Laboratories 1998). The 2900B performs dual channel FFT analysis of up to 400 frequency lines over the range from 0 to a maximum of $20 \mathrm{kHz}$. The $2900 \mathrm{~B}$ is a rugged unit designed for field testing and runs for up to 4 hours using its internal battery pack. Two Larson Davis model PRA950B power tubes were also used to provide the $2 \mathrm{~mA}$ current required by the internal preamplfiers of the ICP accelerometers. The test sensors consisted of four PCB model 336C04 ICP piezoelectric accelerometers, two of which were used in their original form to measure floor vibration and two of which were mounted in pads for measuring vibration at the points of contact with the human occupants. One accelerometer pad was manufactured according to SAE standard J1013 (1974) and was used for measuring the vibrations at the driver's seat cushion. For performing acceleration measurements in the child seat, however, no standard device was available. A child pad was therefore designed and built by scaling the dimensions of the SAE pad to values appropriate for use with children of the age and weight group associated with stage $0 \& 1$ seats. Since the mean inter ischial tuberosity distance for a 12 month old child is less than $141 \mathrm{~mm}$ (Henry Dreyfuss Associates 1993; Society of Automotive Engineers 1977), the outer diameter of the child pad ring was chosen to be $150 \mathrm{~mm}$ and the material was chosen to be 80 shore in hardness as in J1013. The geometric dimensions of the child pad are shown in Figure 1. The weight of the child pad is 224 grams, which increases to 230 when the PCB 336C04 accelerometer is installed.

\section{[insert figure 1 here]}

\section{[insert figure 2 here]}

Each test vehicle was instrumented according to the accelerometer layout shown in Figure 2. Two accelerometers were placed on the floor by means of accelerometer wax which guaranteed rigid mechanical coupling to frequencies in excess of $500 \mathrm{~Hz}$. Both were aligned to measure in the vertical direction. One was placed at the rear bolt of the outermost seat guide rail of the driver's seat 
and the other was placed at the same point of the front passenger's seat. The SAE pad was then adjusted to be under the ischial tuberosities of the driver (the test participant) and the child pad was adjusted to be under the ischial tuberosities of the child. No additional alignment to the vertical was possible for the human interface pads.

The road surface chosen for testing was Mary Street in Sheffield (Giacomin 2000). It is straight and flat for 200 metres, and the pave' (cobblestone) surface provides significant vibrational energy at the seat guides of automobiles for frequencies in excess of $60 \mathrm{~Hz}$. Figure 3 presents two views of the surface, while Figure 4 presents an example of an acceleration power spectral density (PSD) obtained at the seat guide in the vertical direction during one of the $40 \mathrm{~km} / \mathrm{h}$ tests described in this paper.

\section{[insert figure 3 here]}

\section{[insert figure 4 here]}

Eight parents took part in the experiment, each arriving with their personal vehicle, their child seat and the ir child. The general characteristics of the test subjects and vehicles are presented in table 2. The age of the parents ranged from 28 to 42 years with a mean of 34, their height ranged from 1.65 to 1.90 metres with a mean of 1.78 and their mass ranged from 50.8 to 95.0 kilograms with a mean value of 72.0. The age of the children ranged from 8 to 30 months with a mean of 17, their height ranged from 0.60 to 0.91 metres with a mean of 0.75 and their mass ranged from 7.20 to 14.5 kilograms with a mean value of 10.7. All child seats were belt-fastened designs, thus no ISOFIX systems (Bell et. al. 1994) were considered. The child seats were installed on the front passenger seat using the vehicle safety belts according to product instructions. Each vehicle either lacked a passenger side airbag or had its passenger side airbag deactivated by means of its key-operated 
switch. Each volunteer was given a participation form to read and sign before performing any tests. After signing the form, data regarding the test participant, their child and the vehicle were gathered.

\section{[insert table 2 here]}

After installing the test instrumentation a series of drives were performed over the road surface. For each run the participant drove his or her vehicle, maintaining the target speed by means of the vehicle's speedometer. One of the authors sat in the rear of the vehicle operating the test equipment and noting conditions. For the $40 \mathrm{~km} / \mathrm{h}$ tests the spectrum analyzer was set to perform an 18 second acquisition from trigger, while for the $20 \mathrm{~km} / \mathrm{h}$ tests the acquisition time was set at 30 seconds. Since the analyzer was a dual channel device the data for the driver (seat guide and SAE pad) and the child (seat guide and child pad) had to be acquired separately. 16 runs were performed in total; 4 for each seat (driver's or child's) at each test speed (20 or $40 \mathrm{~km} / \mathrm{h}$ ).

The acceleration time histories were sampled at a rate of $400 \mathrm{~Hz}$. Fourier analysis was performed using an FFT block size of 1024 points and a Hanning window. The combination of 1024 point block size and $400 \mathrm{~Hz}$ sampling rate gave a total time window of 2.56 seconds and thus a spectral resolution of $0.391 \mathrm{~Hz}$. All frequency domain results in this paper are presented in the form of power spectral density (amplitude $\left.e^{2} / H z\right)$ rather than power spectra (amplitude). Once in the laboratory, the acquired data were downloaded from the analyzer to a PC for plotting and analysis.

\subsection{Results}

Figures 5 and 6 present the root mean square (r.m.s.) acceleration levels recorded at all four measurement points for all eight tests at $20 \mathrm{~km} / \mathrm{h}$ and at $40 \mathrm{~km} / \mathrm{h}$ in units of $\mathrm{m} / \mathrm{s}^{2}$. The levels measured at the child seat were always higher than those at the driver's seat, and, more importantly, 
the reduction in vibration from floor to human occupant was lower for the child than for the driver in all eight systems tested.

\section{[insert figure 5 here]}

\section{[insert figure 6 here]}

Table 3 summarizes the mean levels measured across the test ensemble. The ratio of the acceleration arriving at the human occupant divided by the acceleration present at the guide of the vehicle seat was $64 \%$ in the case of the driver and $80 \%$ in the case of the child for the $20 \mathrm{~km} / \mathrm{h}$ tests. The same ratio was $59 \%$ for the driver and $74 \%$ for the child at $40 \mathrm{~km} / \mathrm{h}$. The results suggest that the system composed of vehicle seat, child seat and child is less effective at attenuating vibrations than the vehicle primary seating system.

\section{[inert table 2 here]}

Figure 7 presents the mean power spectral density determined for the human interfaces from all eight tests. Comparison of the two sets of results suggests that the child seats transmitted more vibrational energy than the driver's seat at frequencies above $10 \mathrm{~Hz}$, with particularly large differences in the region from 20 to $40 \mathrm{~Hz}$. The increased transmission of vibrational energy in the region from 20 to $40 \mathrm{~Hz}$ is due to child seat frame resonances, as first described by Giacomin (1997a).

\section{[insert figure 7 here]}

The mean power spectral densities measured at the floor and at the human interfaces for each test were used to determine the vertical direction acceleration transmissibility functions. The modulus of 
each ATF was determined by means of the $H_{v}$ spectral estimator which assumes the presence of measurement noise on both the input and output

$$
|A T F(f)|^{2}=\frac{G_{y y}(f)}{G_{x x}(f)}
$$

where $G_{y y}(f)$ is the output PSD and $G_{x x}(f)$ is the input PSD. Figure 8 presents the ATFs estimated from all eight tests from the seat guides to the human interfaces.

\section{[insert figure 8 here]}

From Figure 8 it can be seen that the ATFs are similar across the two test speeds. This suggests that the vibrational energy provided by the road surface was sufficiently high at both test speeds to provide an accurate measurement, and that the overall level of nonlinear behaviour was not too large. These observations are supported by coherence function measurements which were greater than 0.7 in the range from 1 to $40 \mathrm{~Hz}$ and typically higher than 0.6 from 40 to $60 \mathrm{~Hz}$. The ATFs of Figure 8 show higher vibration transmissibility for the child seat than for the driver's seat at frequencies above $10 \mathrm{~Hz}$. In particular, numerous examples of vibration transmissibilities greater than 1 are found at selected frequencies.

Since the vibrational behaviour was somewhat different for each combination of automobile, child seat and child, the ATFs were summarized by means of minimum, mean and maximum transmissibility curves as shown in Figure 9. From the mean curves several observations can be made. The first is that the driver's seats generally provided significant isolation from vibration since mean transmissibilities of $30 \%$ or less were found for all frequencies above $20 \mathrm{~Hz}$. Attenuation also occurred at the lower frequencies with the exception of the two whole-body resonance frequencies 
of the seated adult human body at approximately 3.5 and $12 \mathrm{~Hz}$. The second observation is that the vibration attenuation was not as effective for the child seat system. The ATFs for the child seat rarely dropped below $50 \%$ for frequencies in the range up to $60 \mathrm{~Hz}$.

The mean ATFs of Figure 9 also show that the main resonance frequency observed for the child seats, $8.5 \mathrm{~Hz}$, was higher than that observed for the driver's seats, $3.5 \mathrm{~Hz}$. For the case of adults seated on elastic cushions several studies have identified a first whole-body resonance of the adult body in the frequency interval from approximately 3.0 to $5.0 \mathrm{~Hz}$ (Dupius and Zerlett 1986; Griffin 1990). This response of the adult body in generally accepted to be both a vertical and a fore-and-aft movement of the trunk over the elasticity of the buttocks tissue and cushion. Given the similarities of the transmissibility curves of Figure 9, it might be proposed that a similar behaviour occurs for the child body at approximately $8.5 \mathrm{~Hz}$. The difference in mean resonance frequency would be caused by the anthropometric and postural differences.

Further support for the presence of whole-body resonances of both the adults and the children is found by taking the ratio between the mean ATF for the drivers and that of the children as shown in Figure 10. For the eight systems tested, the ATF ratio shows that the transmissibility to the children was greater than that to the adults at all frequencies except $3.5 \mathrm{~Hz}$ where the child system is missing the resonance response of the adult human body. The ratio also shows a large peak at $8.5 \mathrm{~Hz}$ where the children have their first response resonance.

\author{
[insert figure 9 here] \\ [insert figure 10 here]
}

\title{
4.0 Conclusions
}


Experimental acceleration measurements were performed for 8 combinations of automobile, child seat and child while driving over a pave' (cobblestone) road surface at speeds of 20 and $40 \mathrm{~km} / \mathrm{h}$. Mean results confirm that significant differences exist between the system composed of the vehicle seat, child seat and child with respect to the system composed of driver's seat and driver. The child seat system was found to be less effective in terms of vibration attenuation. The ensemble mean transmissibility in the frequency range from 1 to $60 \mathrm{~Hz}$ was found to be $77 \%$ for the child seat system as opposed to $61 \%$ for the driver's seat.

The mean ATFs, and the ratio of the mean ATFs between child and driver, suggest that the principal whole-body resonance of the children is different from that of the seated adults. The mean resonance frequency measured in the child seats was $8.5 \mathrm{~Hz}$ as opposed to the $3.5 \mathrm{~Hz}$ measured for the adult drivers. This result has implications for the comfort evaluation of child seat systems since all existing whole-body vibration standards (Griffin 1990) are based on frequency weightings developed by means of tests involving adult participants. Frequency weightings such as the vertical direction $\mathrm{W}_{\mathrm{d}}$ of $\mathrm{BS} 6841$ or the vertical direction $\mathrm{W}_{\mathrm{k}}$ of ISO 2631 have a shape which is strongly influenced by the mechanical response resonance frequencies of the adult body. The results of this study suggest that the weightings might not be immediately applicable in the case of children since the mechanical response resonances were found to occur at different frequencies. How comfort should be evaluated in the case of small children or other individuals whose anthropometry is different from that of the test subjects used to develop the current family of international standards therefore remains an open question.

A final comment is that the seats tested were all fastened to the vehicle by means of the vehicle's safety belts. Since this arrangement does not provide rigid mechanical coupling between vehicle and child seat, ample rigid body movements occur. Attachment by systems such as ISOFIX which provide a rigid connection would be expected to result in different vibrational characteristics. 


\subsection{Acknowledgements}

The authors would like to thank Mr. David Nutall for his help in designing and building the child pad. The authors would also like to express their gratitude to all the test participants who offered their time and effort.

\subsection{References}

Bell, R., Burleigh, D. and Czernakowski, W. 1994, ISOFIX: The potential of a universal vehicle/child restraint interface for misuse reduction and performance enhancement. SAE Paper 942220 (Warrandale, PA: Society of Automotive Engineers).

Blaise, T. 2001, Elaboration of a testing procedure with human subjects for seat vibration evaluation. Paper presented at The Role of Experimentation in the Automotive Product Development Process, Associazione Tecnica dell'Automobile $7^{\text {th }}$ International Conference, Florence, Italy, 23-25 May.

Bruncassan, F., Cailleret, M.C. and Tarriere, C. 1992, Contribution of biomechanics to child safety in motor vehicles, Annales de Pediatrie, 39 (3), 165-173

Dupuis, H. and Zerlett, G. 1986, The Effects of Whole-Body Vibration (Berlin: Springer Verlag).

Ewins, D.J. 2000, Modal Testing: Theory and Practice (Baldock, Hertfordshire: Research Studies Press).

Giacomin, J. 2000, Some observations regarding the vibrational environment in child safety seats, Applied Ergonomics, 31, 207-215 
Giacomin, J. 1997a, Modal properties of child safety seats. Paper presented at Comfort in the Automobile Industry, Associazione Tecnica dell' Automobile $4^{\text {th }}$ International Conference, Bologna, Italy, 2-3 October, 415-425.

Giacomin, J. 1997b, In-vehicle measurement of the apparent mass of small children. Paper presented at the United Kingdom Group Meeting on Human Response to Vibration, ISVR, University of Southampton, United Kingdom, 17-19 September.

Giacomin, J. and Bracco, R. 1995, An experimental approach for the vibration optimisation of automotive seats. Paper presented at Vehicle Comfort and Ergonomics, Associazione Tecnica dell'Automobile $3^{\text {rd }}$ International Conference, Bologna, Italy, 29-31 March, 199-208.

Griffin, M.J. 1990, Handbook of Human Vibration (London: Academic Press).

Henry Dreyfuss Associates 1993, The Measure of Man and Woman (New York: Henry Dreyfuss Associates).

Kuhane, C.J. 1986, An Evaluation of Child Passenger Safety: the Effectiveness and Benefits of Safety Seats, DOT-HS-806-890 (Washington D.C.: National Highway Traffic Safety Administration).

Larson Davis Laboratories 1998, Model 2900B User Manual (Provo Utah: Larson Davis Laboratories).

Society of Automotive Engineers 1974, Measurement of whole body vibration of the seated operator of agricultural equipment, The Society of Automotive Engineers SAE J1013 Handbook Part II, (Warrandale, PA: Society of Automotive Engineers).

Society of Automotive Engineers 1977, Anthropometry of infants, children and youths to age 18 for product safety design (Warrandale, PA: Society of Automotive Engineers). 


\begin{tabular}{|c|c|c|c|}
\hline Stage & Installation & Child weight & Child age \\
\hline 0 & rearward facing & $0-13 \mathrm{~kg}$ & $0-15$ months \\
\hline $0 \& 1$ & rearward facing / forward facing & $1-18 \mathrm{~kg}$ & $0-4$ years \\
\hline 1 & forward facing & $9-18 \mathrm{~kg}$ & 9 months -4 years \\
\hline 2 & forward facing & $15-25 \mathrm{~kg}$ & $4-6$ years \\
\hline 3 & forward facing & $22-36 \mathrm{~kg}$ & $6-11$ years \\
\hline
\end{tabular}

Table 1) System of stages used to define age and weight limits for child safety seats in the United Kingdom

\begin{tabular}{|c|c|c|c|c|c|c|c|c|}
\hline & Test 1 & Test 2 & Test 3 & Test 4 & Test 5 & Test 6 & Test 7 & Test 8 \\
\hline Driver & & & & & & & & \\
\hline $\operatorname{Sex}(M / F)$ & M & M & M & M & M & $\mathrm{F}$ & F & $\mathrm{F}$ \\
\hline Age (years) & 29 & 28 & 35 & 35 & 42 & 29 & 40 & 37 \\
\hline Height (m) & 1.81 & 1.86 & 1.90 & 1.90 & 1.82 & 1.65 & 1.65 & 1.65 \\
\hline Mass (kg) & 70.0 & 72.0 & 77.6 & 77.6 & 78.0 & 55.0 & 50.8 & 95.0 \\
\hline Child & & & & & & & & \\
\hline $\operatorname{Sex}(M / F)$ & M & M & M & $\mathrm{F}$ & $\mathrm{F}$ & M & M & M \\
\hline Age (months) & 8 & 8 & 9 & 24 & 30 & 10 & 36 & 9 \\
\hline Height (m) & 0.68 & 0.60 & 0.65 & 0.85 & 0.90 & 0.70 & 0.91 & 0.70 \\
\hline Weight (kg) & 7.5 & 7.2 & 10.0 & 14.5 & 13.0 & 12.0 & 13.6 & 8.0 \\
\hline Seat & - & Maxi & Britax & Britax & Mother-care & - & Britax & Klippan \\
\hline Vehicle & & & & & & & & \\
\hline Model & $\begin{array}{l}\text { Volks Golf } \\
\text { 5D }\end{array}$ & $\begin{array}{l}\text { Vauxhall } \\
\text { Corsa 3D }\end{array}$ & $\begin{array}{c}\text { Mazda } 626 \\
5 \mathrm{D}\end{array}$ & $\begin{array}{c}\text { Mazda } 626 \\
5 \mathrm{D}\end{array}$ & $\begin{array}{c}\text { Volvo } 940 \\
\text { 5D }\end{array}$ & $\begin{array}{c}\text { Honda Civic } \\
\text { 3D }\end{array}$ & $\begin{array}{l}\text { Vauxhall } \\
\text { Corsa 3D }\end{array}$ & $\begin{array}{c}\text { Mitsubishi } \\
\text { Space Wagon }\end{array}$ \\
\hline Tyres & $\begin{array}{l}\text { Michelin } \\
\text { 175/70 R13 }\end{array}$ & - & $\begin{array}{c}\text { Bridge-stone } \\
185 / 65 \text { R15 }\end{array}$ & $\begin{array}{c}\text { Bridge-stone } \\
185 / 65 \text { R15 }\end{array}$ & $\begin{array}{c}\text { Goodyear } \\
185 / 65 \text { R19 }\end{array}$ & $\begin{array}{c}\text { Centaur } \\
175 / 70 \text { R13 }\end{array}$ & $\begin{array}{c}\text { Michelin } \\
\text { 145/80 R13 }\end{array}$ & $\begin{array}{c}\text { Indian GT70 } \\
185 / 70 \text { R14 }\end{array}$ \\
\hline Odometer (km) & 195,691 & 157,281 & 15,438 & 15,438 & 199,232 & 72,362 & 51,983 & 158,633 \\
\hline
\end{tabular}

Table 2 Characteristics of the drivers, children and vehicles tested. 


\begin{tabular}{|l|c|c|c|c|}
\hline & \multicolumn{2}{|c|}{$20 \mathrm{~km} / \mathrm{h}$ Tests } & \multicolumn{2}{c|}{$40 \mathrm{~km} / \mathrm{h}$ Tests } \\
\hline & Mean value & Std. & Mean value & Std. \\
\hline Driver's seat & 1.07 & 0.18 & 1.41 & 0.27 \\
\hline Driver's seat guide & 1.66 & 0.31 & 2.40 & 0.36 \\
\hline Child seat guide & 1.80 & 0.39 & 2.50 & 0.40 \\
\hline Child seat & 1.44 & 0.28 & 1.86 & 0.34 \\
\hline
\end{tabular}

Table 3) Mean and standard deviation of the r.m.s. acceleration levels determined from all tests.
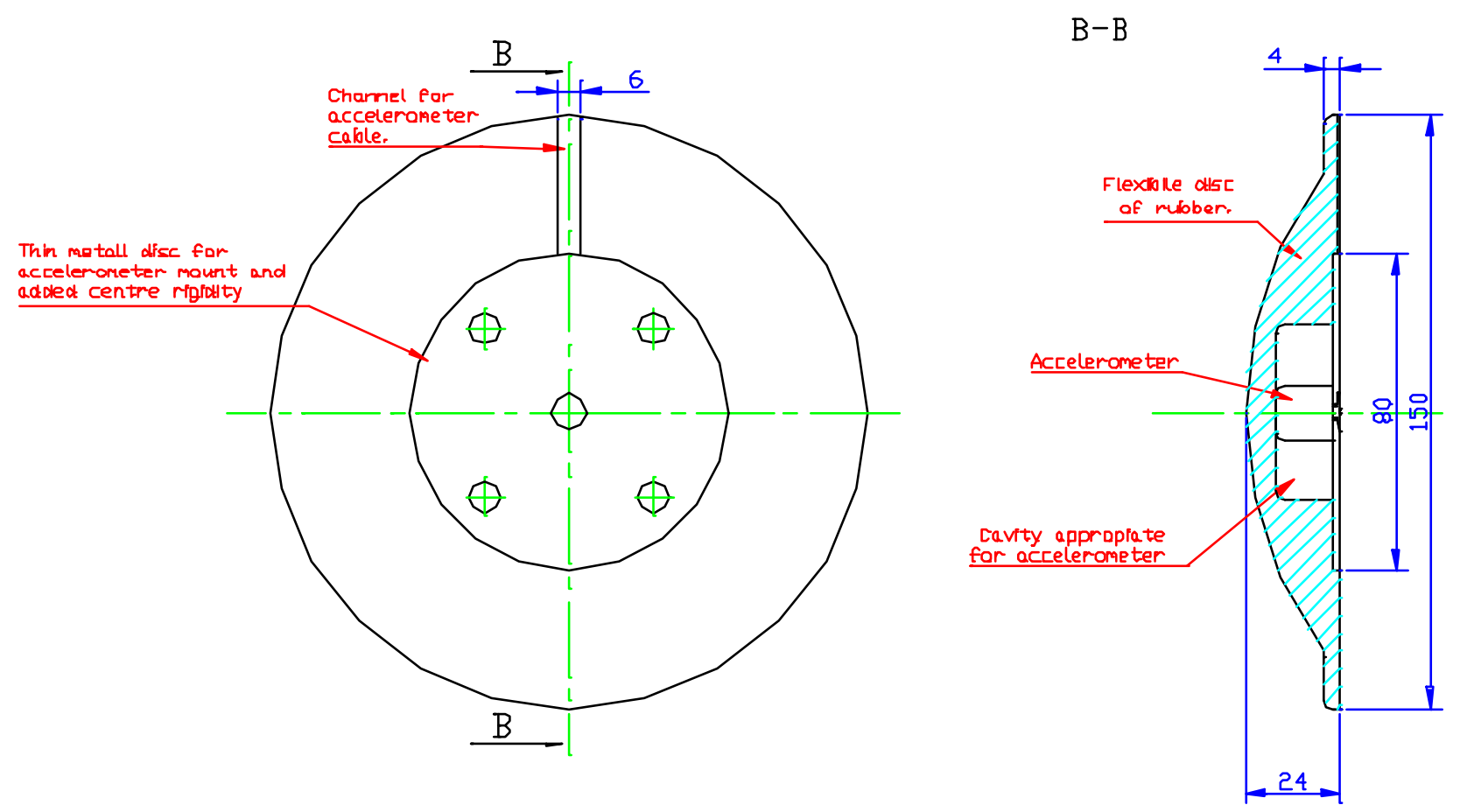

Figure 1) Child-pad used for measuring the vibration at the interface between child seat and child. All dimensions are in millimetres. 


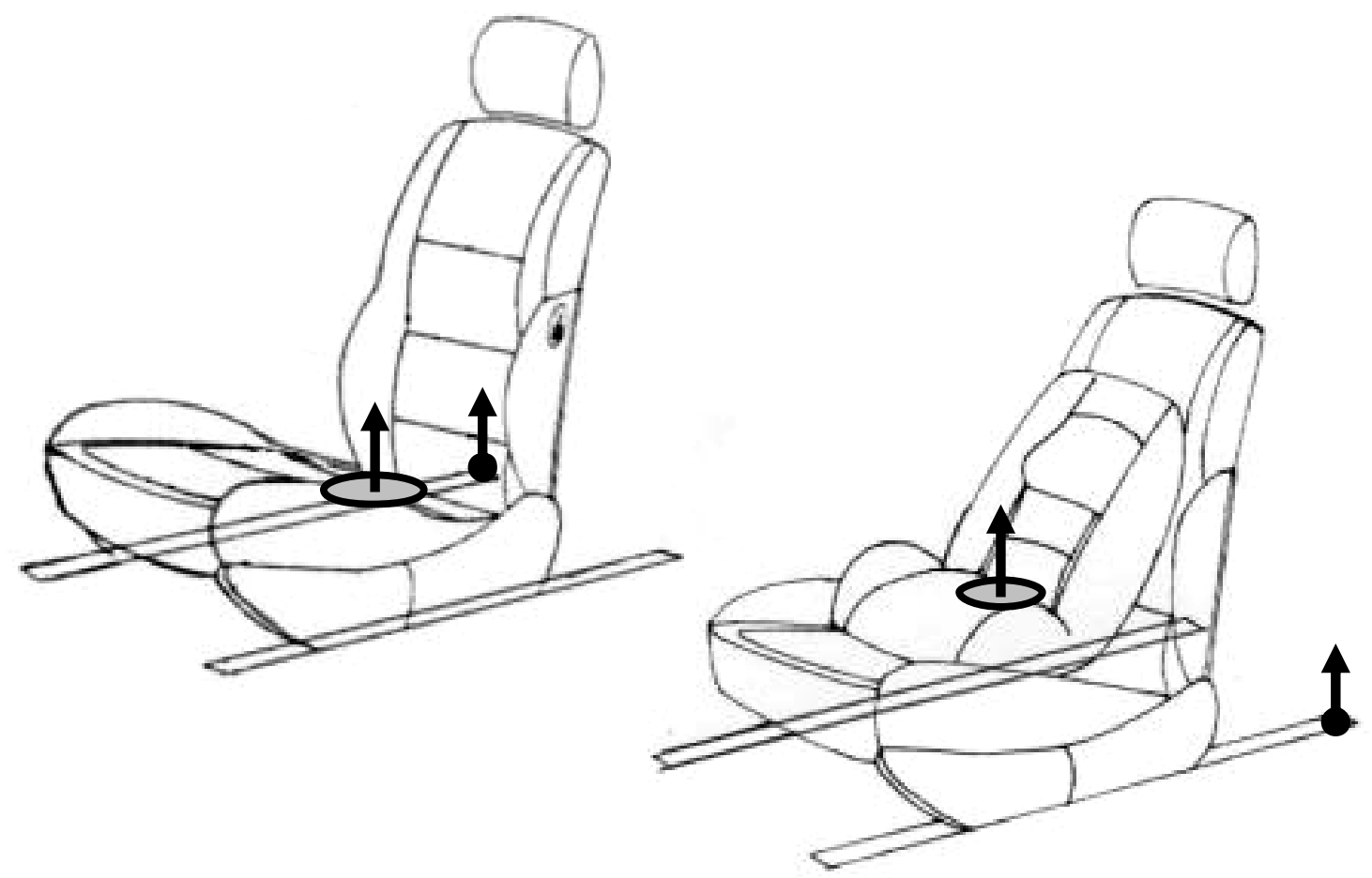

Figure 2) Accelerometer layout used for the driver's and child seats.
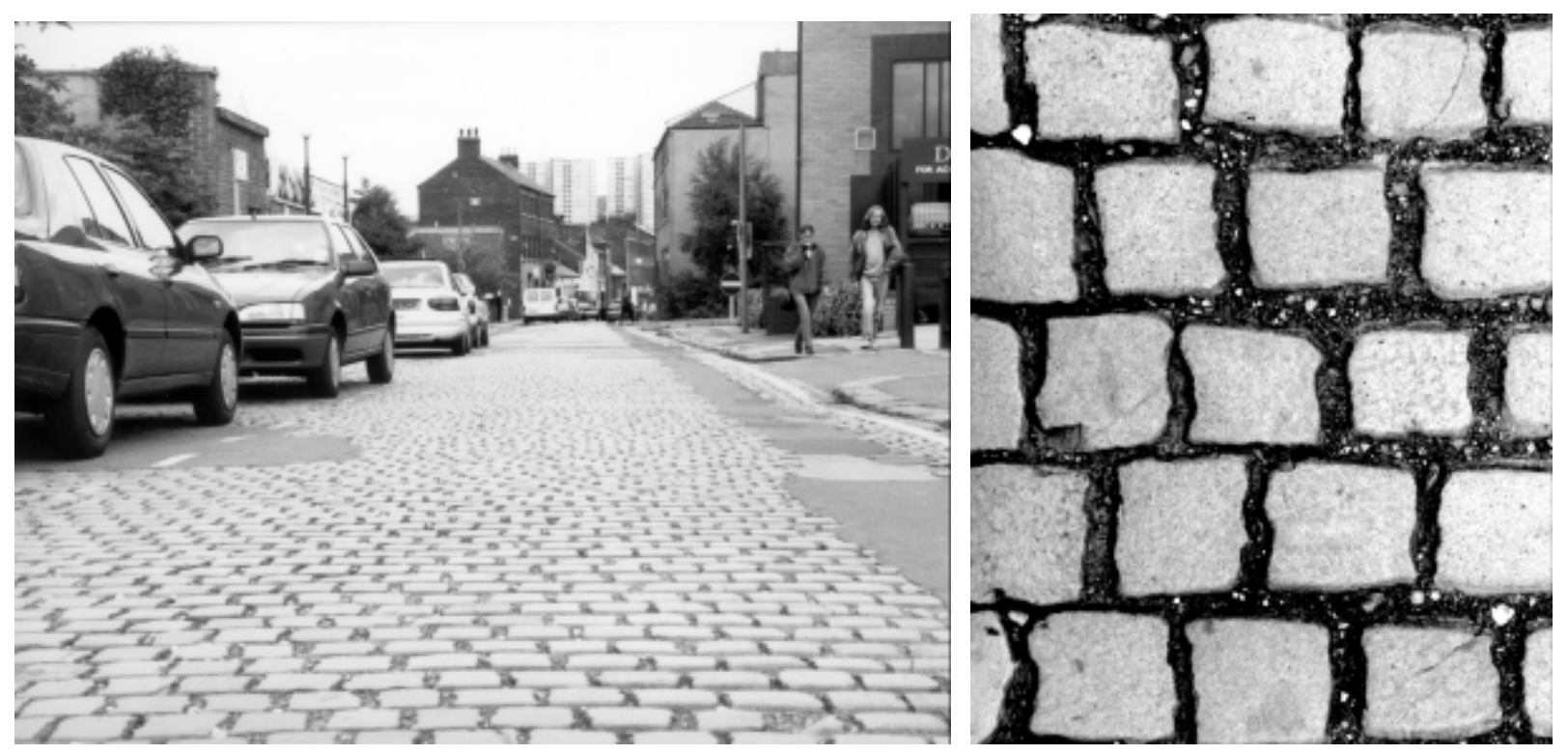

Figure 3) Two views of the Mary Street pave' road surface. 


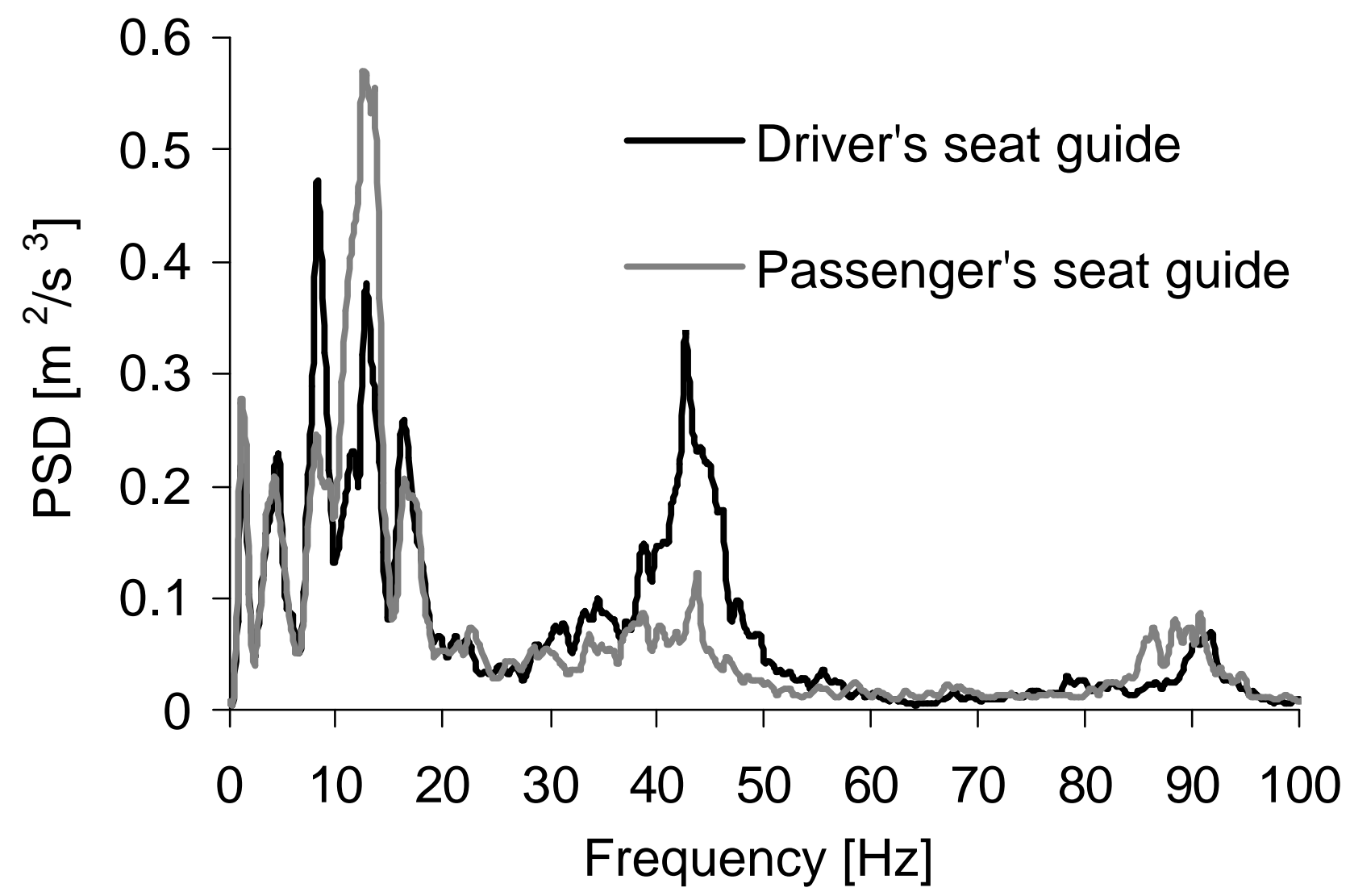

Figure 4) Vertical acceleration PSD measured at the seat guides during one test run on the pave' road surface at $40 \mathrm{~km} / \mathrm{h}$. 


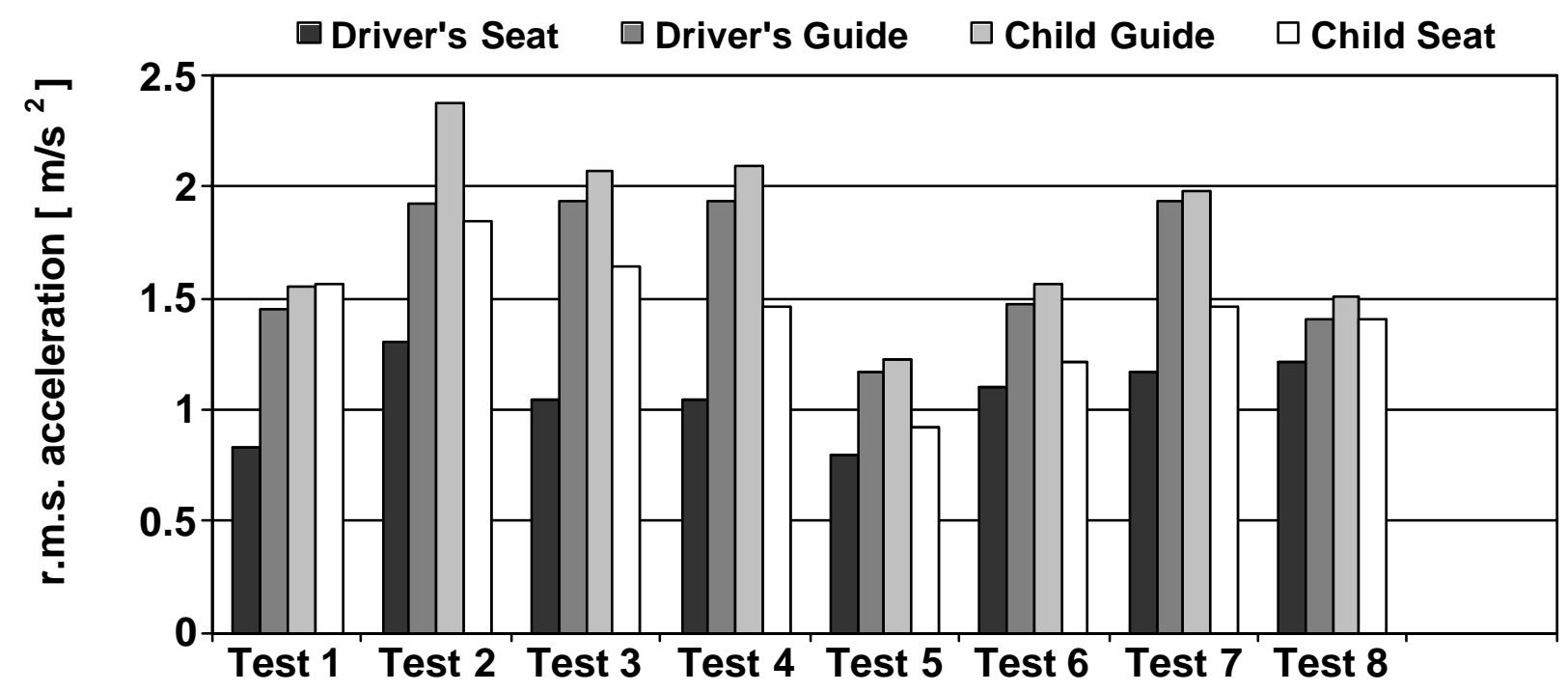

Figure 5) The r.m.s. acceleration level at each measurement point for each of the eight in- vehicle tests performed at $20 \mathrm{~km} / \mathrm{h}$.

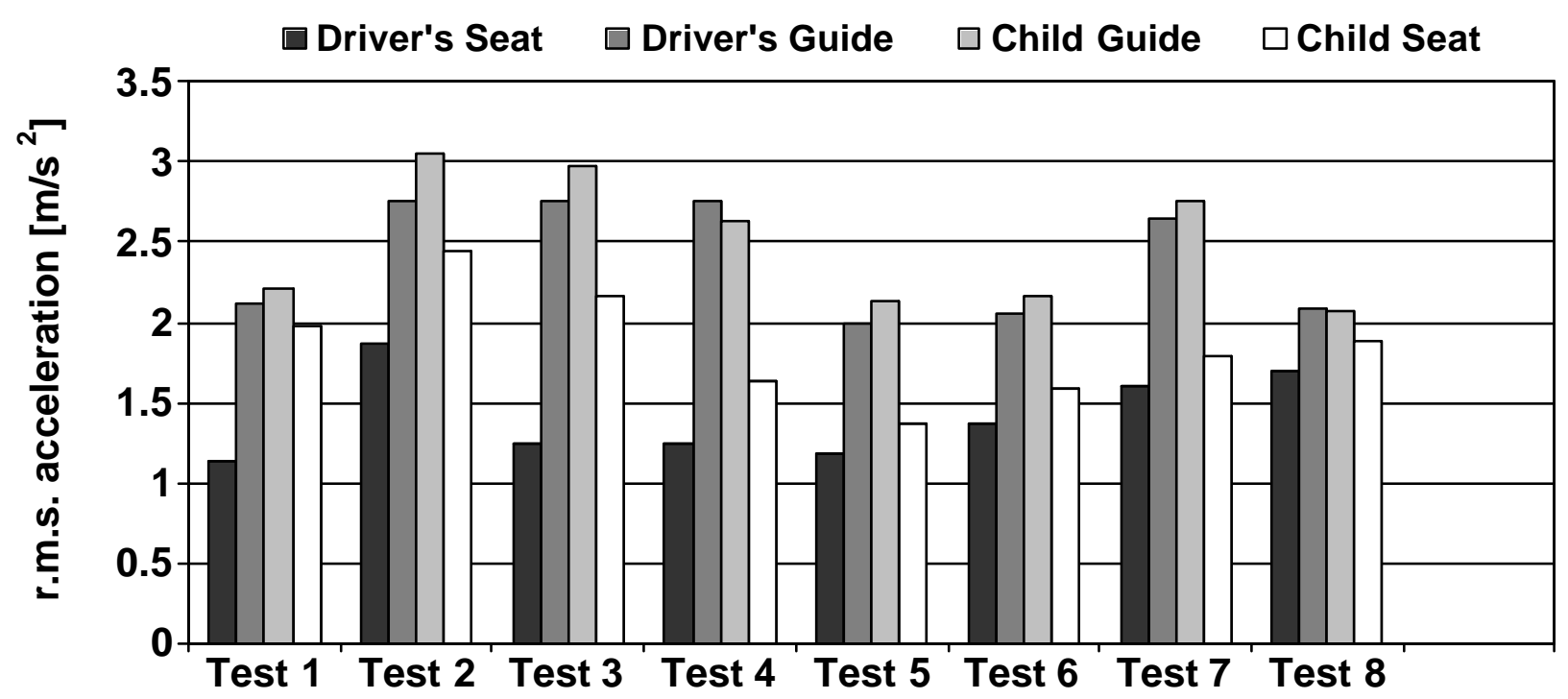

Figure 6) The r.m.s. acceleration level at each measurement point for each of the eight in- vehicle tests performed at $40 \mathrm{~km} / \mathrm{h}$. 

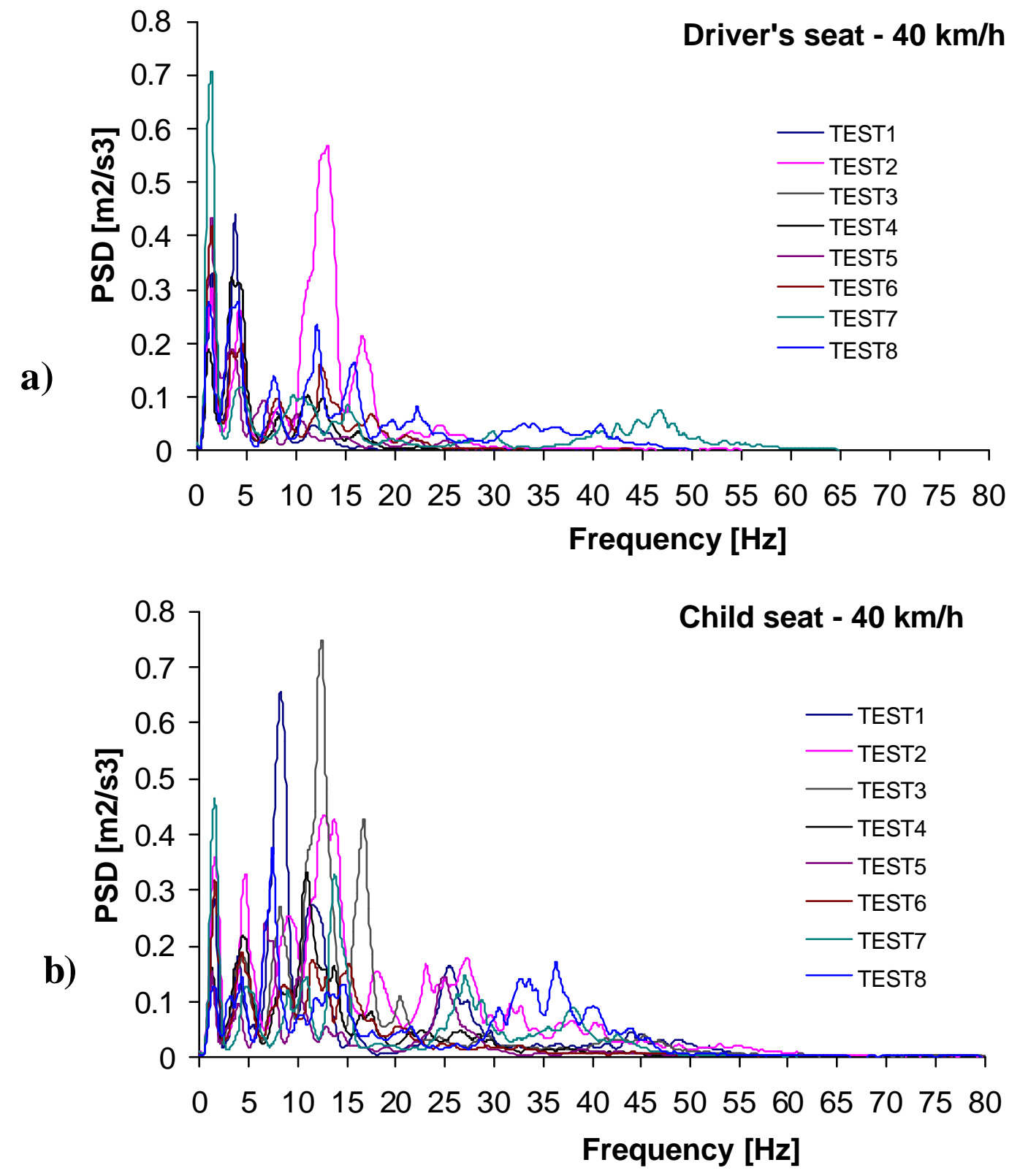

Figure 7) a) Acceleration power spectral densities measured at the driver's seat at $40 \mathrm{~km} / \mathrm{h}$ b) Acceleration power spectral densities measured at the child seat at $40 \mathrm{~km} / \mathrm{h}$ 


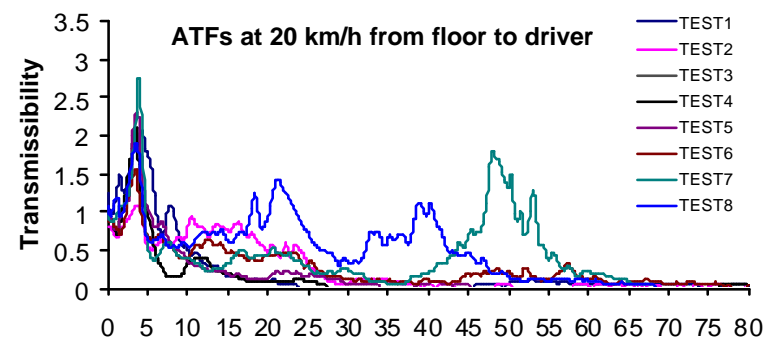

Frequency [Hz]

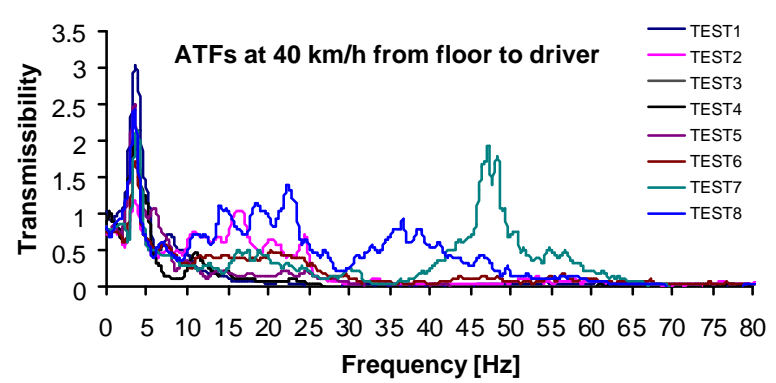

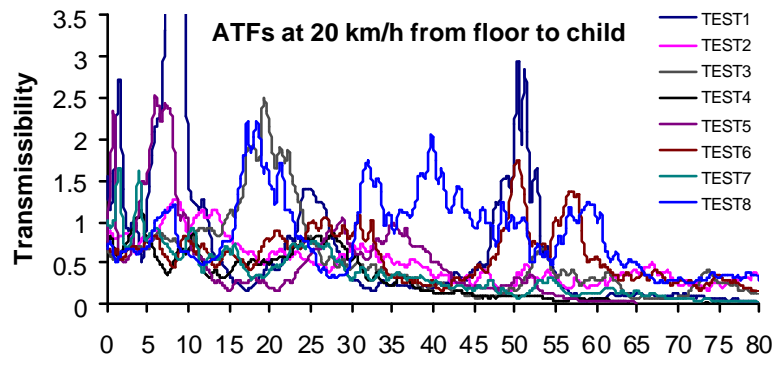

Frequency [Hz]

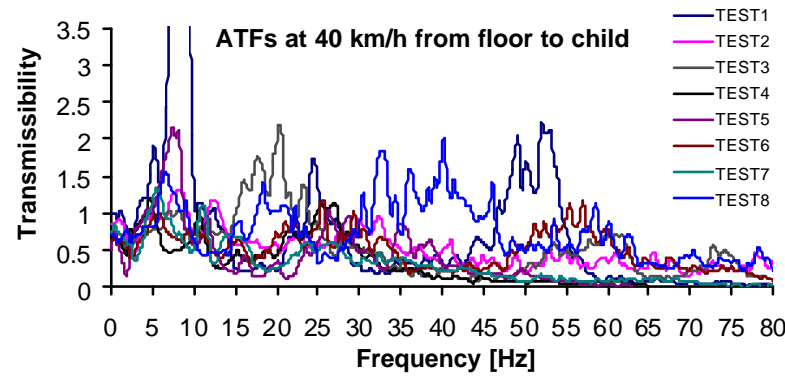

Figure 8) Acceleration transmissibility functions from the floor to the human interfaces at 20 and $40 \mathrm{~km} / \mathrm{h}$. 

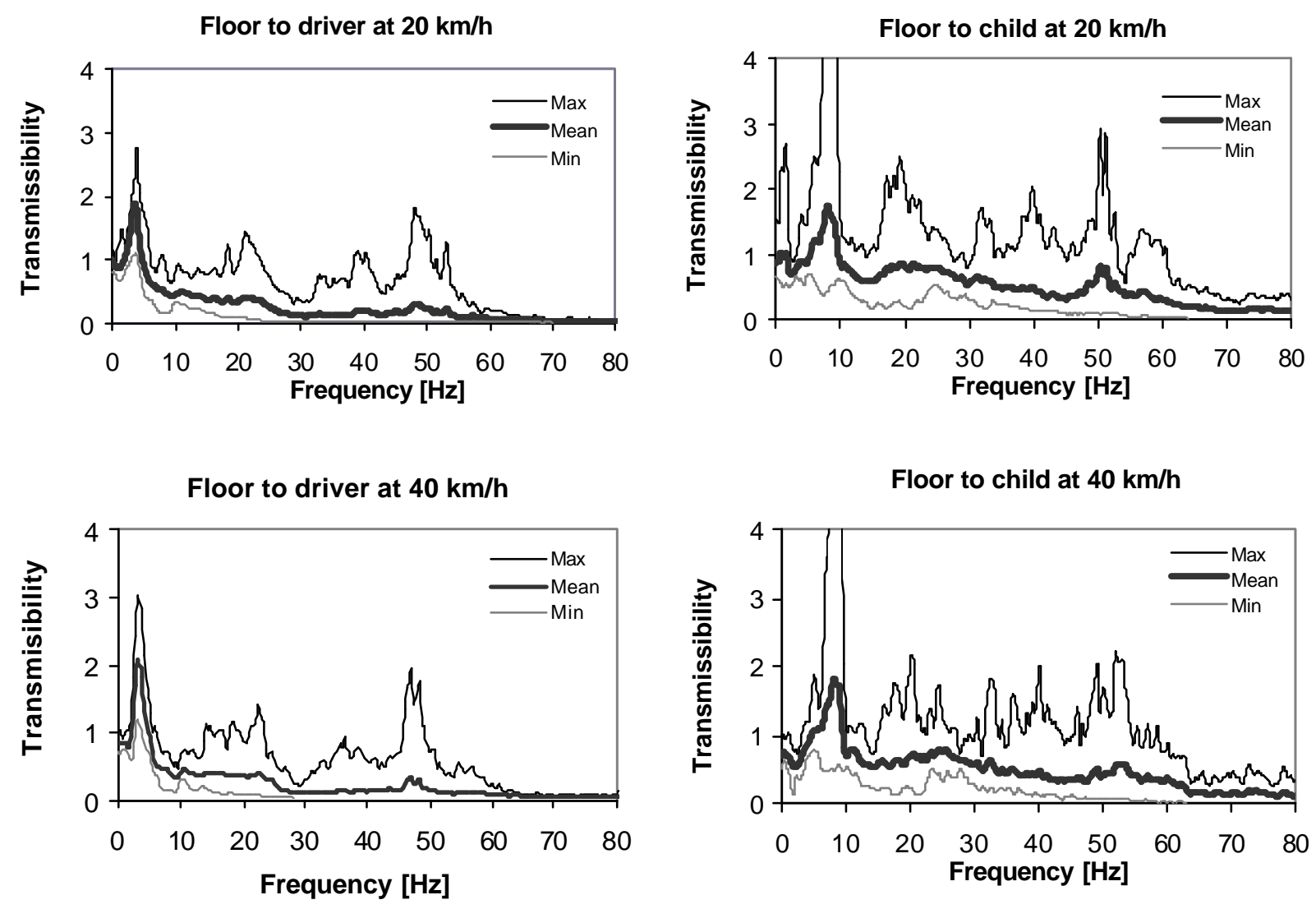

Figure 9) Minimum, mean and maximum acceleration transmissibility functions calculated from the floor to the human interfaces from all data. 


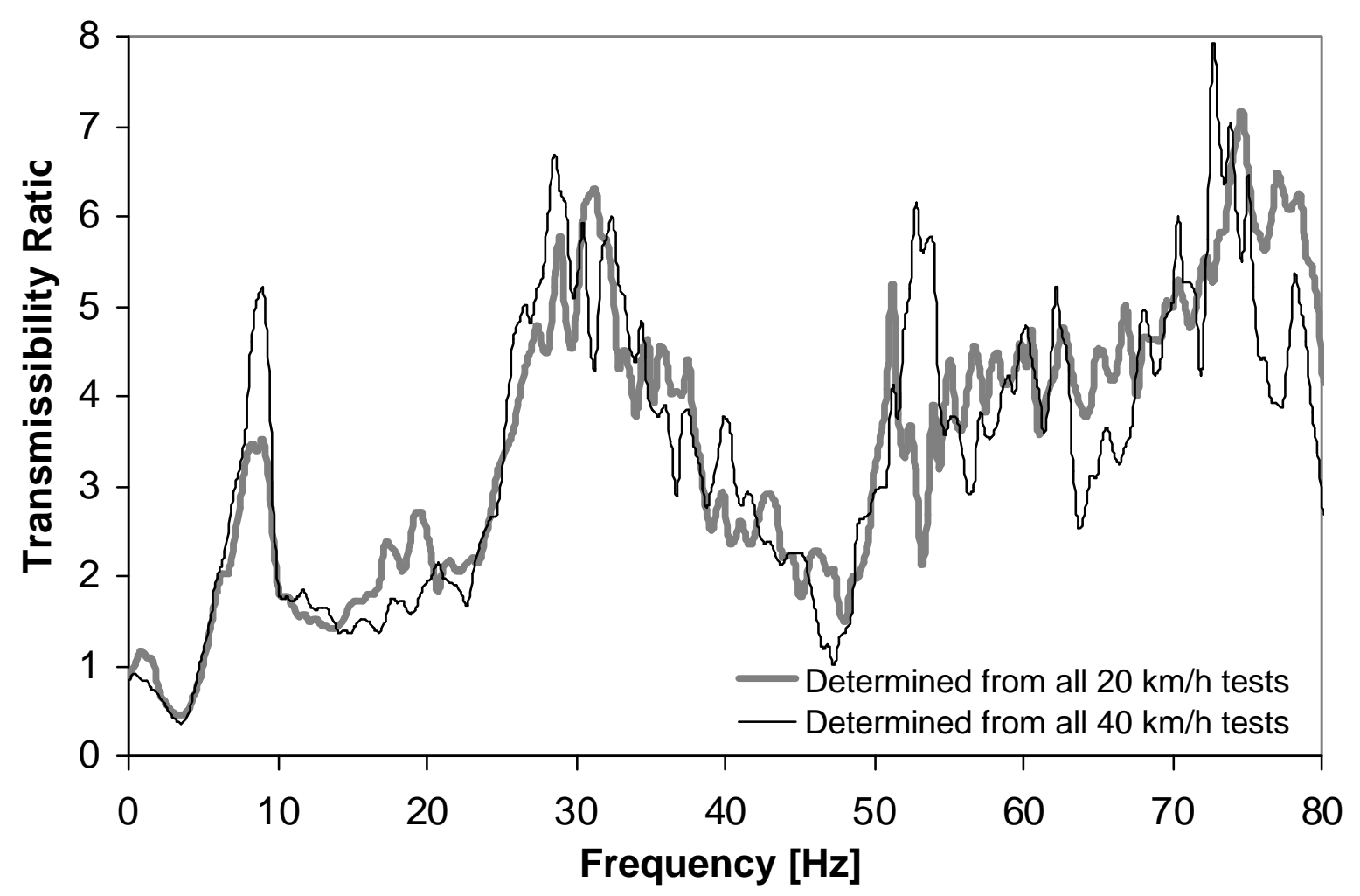

Figure 10) Ratio between the mean ATF to the driver and the mean ATF to the child. 